\title{
Study of the Impact of Liver Cirrhosis on Health-Related Quality of Life in Chronic Hepatic Patients, Menoufia Governorate
}

\author{
Mohamed Alaa Eldin Nouh ${ }^{1}$, Amira Maher Badawy, \\ Hala Marwan Mohamed ${ }^{2}$, Sherien Abd El-Aziz El-Kashash ${ }^{1}$ \\ ${ }^{1}$ Tropical Medicine Department, Faculty of Medicine, Menoufiya University, Egypt. \\ ${ }^{2}$ Public Health Department, Faculty of Medicine, Menoufiya University,Egypt.
}

Corresponding Author Sherien Abd El-Aziz El-Kashash

Mobile: 01006660886

E mail:

dr.Shosho3@yahoo.com

Key words: Cirrhosis-Quality of life-SF-36-Child score
Background and study aim: cirrhosis is associated with morbidity and mortality and complications of cirrhosis. Healthrelated quality of life should be considered an important outcome measure in the treatment of cirrhotic patients. This study is designed to assess the impact of liver cirrhosis on a weighted score of health - related quality of life in those patients.

Patients and Methods: This study was conducted on four groups of patients and control subjects. Group I included 50 Child A liver cirrhosis. Group II included 50 Child B cirrhosis. Group III included 50 Child C liver cirrhosis. Group IV as healthy control subjects. All patients and control subjects completed a Medical

\section{INTRODUCTION}

Cirrhosis is a serious disease that is associated with significant morbidity and mortality. Patients may suffer from specific complications of cirrhosis such as (hepatic encephalopathy, ascites and variceal bleedings. Furthermore, fatigue, joint pain, pruritis, loss of appetite, depression, abdominal pain, worries about complications of the disease, decreased sexual interest and activity, loneliness, hopelessness, problems with social interaction and problems with memory and concentration) have been associated with Chronic liver disease [1].

Quality of life has an inherent meaning to most people. It is comprised of broad concepts that affect global life satisfaction, including good health, adequate housing, employment, personal and family safety, interrelationships, education, and leisure pursuits. For
Outcomes Study Short Form 36 (SF-36) questionnaires used for measuring the health related quality of life.

Results: There was a highly significant decrease in the short form-36 questionnaire score of health related quality of life with the Child score progression in comparison to other healthy persons, There was statistical significant positive correlation between The SF-36 scores (vitality (energy/fatigue) scale and physical functioning scale) and occupation and education level.

Conclusions: cirrhosis reduced the quality of life of the patients; advanced Child score and development of complications have a negative effect in their quality of life.

matters related to health care, quality of life has been applied specifically to those life concerns that are most affected by health or illness, hence the term "health-related quality of life" [2].

Health-related quality of life refers to the subjective assessment of patients regarding the physical, mental and social dimensions of well-being. It has become an important measure in clinical and epidemiological studies in gastroenterology and hepatology [3].

Health-related quality of life refers to a patient's /the patient's perception of his/her state of health the assessment is not limited to medical interventions. The perception of quality of life varies between individuals and is dynamic. Individuals who present with the same clinical picture have different expectations and report different qualities of life [4]. 
The quality of life of the patients were evaluating from the point of view of the patients, their family, and their care takers to find appropriate interventions, and training and counselling programme to support patients [5].

\section{PATIENTS AND METHODS}

This study was carried out on patients attending the outpatient clinic and inpatient of Shebin ElKom Fever Hospital and patient admitted at Endemic Medicine Department, Menoufia University Hospitals in the period between April to December 2014, from which 150 cirrhotic patients were selected, in addition to 50 healthy persons of matched age and sex as controls. The patients were further subdivided into three groups. Group I included 50 Child A patients, Group II included 50 Child B patients , group III included 50 Child $\mathrm{C}$ patients and group IV included 50 healthy persons as controls.

After have an informed consent, all patients and controls were subjected to full history taking, full clinical examination, abdominal ultrasonography, and laboratory investigations including: CBC, ESR, RBS, liver function tests, Alfa feto protein, urine ,kidney function, Prothrombin time and concentration, bilirubin, $\mathrm{HCV} \mathrm{Ab} \&$ RNA. HBs $\mathrm{Ag}$ and core antibodies, HBV-DNA, International normalized ratio, TSH, Iron, Transferritin, Alkaline phosphatise, Gamma glutamyl transferase, Fasting total cholesterol, ceruloplasmine and the medical study short form (SF-36).

\section{Exclusion criteria}

- Patients with hepatic encephalopathy.

- Patients with unrelated psychological disturbance.

- Chronic medical or inflammatory disease.

\section{Sample collection and measurement of quality of life}

The questionnaire was translated into Arabic, Patients in outpatient clinic took a copy to home to complete it and brought it in the next visit while inpatients completed it inside the hospital and for each patient. The SF-36 questionnaire consists of 36 questions (items) measuring physical and mental health status in relation to eight health concepts (physical functioning, role limitations due to physical health, bodily pain, social functioning, role limitations due to emotional health, general health scale, physical functioning, vitality (energy/fatigue), general mental health (psychological distress/wellbeing) [6].

\section{Statistical analysis :}

Data were collected, tabulated, statistically analyzed by computer using SPSS version 22, two types of statistics were done:

1- Descriptive statistics:

Quantitative data expressed to measure the central tendency of data and diversion around the, mean (x) and standard deviation (SD). Qualitative data expressed in number and percentage.

\section{2- Analytic statistics:}

- Student test was used for comparison of two groups of normally distributed variables, chisquare (x2) was used to compare categorical outcomes.

- ANOVA test was used for comparison of more than two groups of normally distributed variables, post hoc (Scheffee test) was used to test significance between individual groups.

- Spearman correlation (r) was used to detect association between quantitative variable and ordinal qualitative variable.

The level of significance: $\mathrm{p}<0.05, \mathrm{P}<0.001$.

\section{RESULTS}

There was a high statistically significant past history of hematemesis ,jaundice and anti bilharzial treatment in hepatic patients in comparison with control group as shown in table $(1)(\mathrm{P}<0.001)$.

There was a high statistically significant difference on the short form 36 (SF-36) questionnaires as regarding to physical functioning, role of limitation due to physical functioning, bodily pain scale, general health scale of quality of life among studied groups that were collected from them as shown in table (2).

There was no statistical significance between group 1 (Child A) and group 4 (controls) in all scores of the short form 36 (SF-36) questionnaires (physical functioning, role of limitation due to physical functioning, bodily pain scale, general health scale, vitality scale, social functioning scale, mental health scale) of quality of life with highly significance in emotional problems limitation scale.

On the other hand, there was a high statistical significance on the short form 36 (SF-36) questionnaires as regarding vitality scale, social functioning scale, role of limitation due to emotional problems scale, mental health scale of quality of life among studied groups that were 
collected from them( $\mathrm{p}$ value $<0.001)$ as shown in figure (1).

There was statistical significant positive correlation between the education and the parameters of the SF-36 scores as regard to the vitality (energy/ fatigue) scale and physical functioning scale ( $\mathrm{p}$ value $<0.05)$ as shown in table (3).
There was statistical significant positive correlation between the occupation and the parameters of the SF-36 scores as regard to the vitality (energy/ fatigue) scale and physical functioning scale( $\mathrm{p}$ value $<0.05$ ) as shown in table (4).

Table (1): Shows the results of Risk factor and related past history in the studied groups

\begin{tabular}{|c|c|c|c|c|}
\hline $\begin{array}{c}\text { Studied past history } \\
\text { variables }\end{array}$ & Controls (50) & $\begin{array}{c}\text { Patients } \\
(\mathbf{1 5 0})\end{array}$ & $\mathbf{X}^{\mathbf{2}}$ test & P value \\
\hline $\begin{array}{c}\text { Anti bilharzial } \\
\text { Treatment injections }\end{array}$ & 0 & & & \\
Yes & 50 & 67 & 9.21 & $<0.001^{* *}$ \\
No $\quad$ Yes $\quad$ No & 50 & 83 & & $<0.001^{* *}$ \\
\hline Jaundice : $\quad 0$ & 53 & 20.43 & $<0.001^{* *}$ \\
\hline Haematemesis: Yes & 50 & 62 & 10.76 & \\
\hline
\end{tabular}

** Highly significant difference

Table (2): SF-36 scores in the studied groups of patients regarding to physical functioning, role of limitation due to physical function, bodily pain and general health scale of quality of life among studied groups

\begin{tabular}{|c|c|c|c|c|c|c|c|}
\hline & $\begin{array}{l}\text { Group } 1 \\
\text { Child A } \\
(\mathbf{5 0}) \\
\end{array}$ & $\begin{array}{c}\text { Group } 2 \\
\text { Child B } \\
(50) \\
\end{array}$ & $\begin{array}{c}\text { Group } 3 \\
\text { Child C (50) }\end{array}$ & $\begin{array}{c}\text { Group } 4 \\
\text { Controls } \\
(\mathbf{5 0}) \\
\end{array}$ & ANOVA & $P$ value & Post hoc test \\
\hline $\begin{array}{l}\text { Physical } \\
\text { functioning }\end{array}$ & $\begin{array}{l}91.23 \\
\pm 3.75\end{array}$ & $\begin{array}{l}76.85 \\
\pm 1.53\end{array}$ & $\begin{array}{l}53.65 \\
\pm 8.74\end{array}$ & $\begin{array}{l}93,60 \\
\pm 4.03\end{array}$ & 76.98 & $<0.001 * *$ & $\begin{array}{c}\mathrm{P} 1>0.05 \\
\mathrm{P} 2<0.001 * * \\
\mathrm{P} 3<0.001 * * \\
\mathrm{P} 4<0.001 * * \\
\mathrm{P} 5<0.001 * * \\
\mathrm{P} 6<0.001 * *\end{array}$ \\
\hline $\begin{array}{l}\text { Role of } \\
\text { limitation due to } \\
\text { physical } \\
\text { function }\end{array}$ & $\begin{array}{l}92.20 \\
\pm 2.37\end{array}$ & $\begin{array}{l}76.80 \\
\pm 1.39\end{array}$ & $\begin{array}{l}52.90 \\
\pm 2.22\end{array}$ & $\begin{array}{l}93.25 \\
\pm 2.87\end{array}$ & 756.00 & $<0.001 * *$ & $\begin{array}{c}\mathrm{P} 1>0.05 \\
\mathrm{P} 2<0.001 * * \\
\mathrm{P} 3<0.001 * * \\
\mathrm{P} 4<0.001 * * \\
\mathrm{P} 5<0.001 * * \\
\mathrm{P} 6<0.001 * *\end{array}$ \\
\hline $\begin{array}{l}\text { Bodily pain } \\
\text { scale }\end{array}$ & $\begin{array}{l}90.40 \\
\pm 2.64\end{array}$ & $\begin{array}{l}77.10 \\
\pm 1.62\end{array}$ & $\begin{array}{l}60.65 \\
\pm 4.69\end{array}$ & $\begin{array}{l}92.20 \\
\pm 3.51\end{array}$ & 231.39 & $<0.001 * *$ & $\begin{array}{c}\mathrm{P} 1>0.05 \\
\mathrm{P} 2<0.001 * * \\
\mathrm{P} 3<0.001 * * \\
\mathrm{P} 4<0.001 * * \\
\mathrm{P} 5<0.001 * * \\
\mathrm{P} 6<0.001 * *\end{array}$ \\
\hline $\begin{array}{l}\text { General health } \\
\text { scale }\end{array}$ & $\begin{array}{l}90.60 \\
\pm 1.90\end{array}$ & $\begin{array}{l}76.85 \\
\pm 1.31\end{array}$ & $\begin{array}{l}62.05 \\
\pm 4.77\end{array}$ & $\begin{array}{l}94.21 \\
\pm 4.12\end{array}$ & 321.43 & $<0.001 * *$ & $\begin{array}{c}\mathrm{P} 1>0.05 \\
\mathrm{P} 2<0.001 * * \\
\mathrm{P} 3<0.001 * * \\
\mathrm{P} 4<0.001 * * \\
\mathrm{P} 5<0.001 * * \\
\mathrm{P} 6<0.001 * *\end{array}$ \\
\hline
\end{tabular}

\section{** Highly significant difference}

P1: Probability for comparison between G1 and G4

P3 Probability for comparison between G3and G4

P5 Probability for comparison between G1 and G3
P2: Probability for comparison between G2and G4 P4 Probability for comparison between G1 and G2 P6 Probability for comparison between G2nd G3 


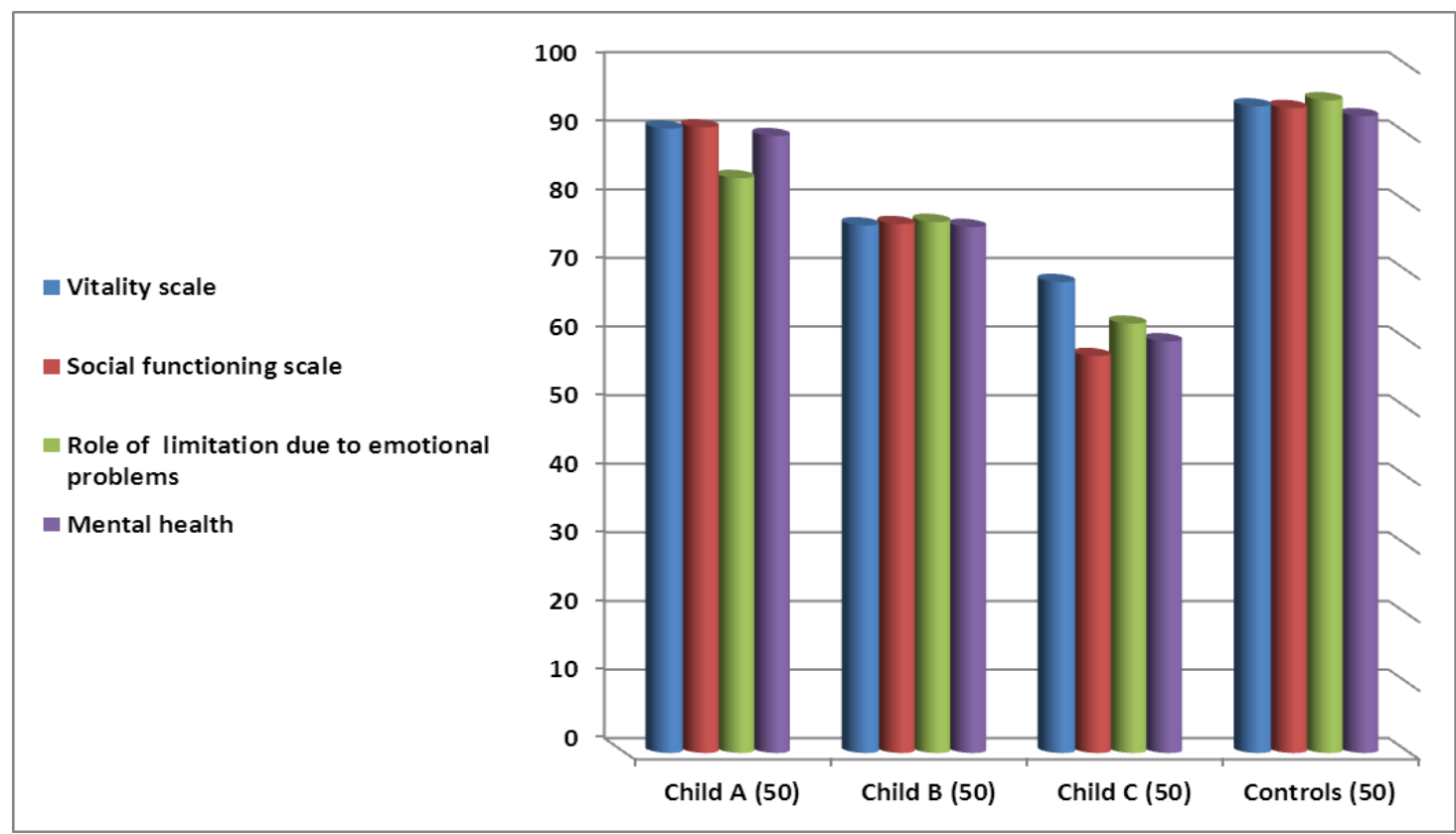

Figure (1)

SF-36 scores in the studied groups of patients regarding to vitality scale, social functioning scale, role of limitation due to emotional problems and mental health scale of quality of life among studied groups:

Table (3): SF-36 scores in correlation to education in the studied patients

\begin{tabular}{|l|c|c|}
\hline \multicolumn{1}{|c|}{ Educational level } & Spearman Correlation(r) & P value \\
\hline Physical functioning & 0.432 & $<0.05^{*}$ \\
\hline Role physical scale & $0.175-$ & $>0.05$ \\
\hline Bodily pain scale & $0.203-$ & $>0.05$ \\
\hline General health scale & 0.165 & $>0.05$ \\
\hline Vitality scale & 0.415 & $<0.05^{*}$ \\
\hline Social functioning scale & 0.175 & $>0.05$ \\
\hline Role emotional scale & 0.123 & $>0.05$ \\
\hline Mental health & $0.136-$ & $>0.05$ \\
\hline
\end{tabular}

* Significant difference

Table (4): SF-36 scores in correlation to the occupation in the studied patients

\begin{tabular}{|l|c|c|}
\hline \multicolumn{1}{|c|}{ Occupation } & Spearman Correlation (r) & P value \\
\hline Physical functioning & 0.495 & $<0.05^{*}$ \\
\hline Role physical scale & $0.143-$ & $>0.05$ \\
\hline Bodily pain scale & 0.214 & $>0.05$ \\
\hline General health scale & 0.178 & $>0.05$ \\
\hline Vitality scale & 0.483 & $<0.05^{*}$ \\
\hline Social functioning scale & 0.183 & $>0.05$ \\
\hline Role emotional scale & 0.145 & $>0.05$ \\
\hline Mental health & $0.162-$ & $>0.05$ \\
\hline
\end{tabular}

* Significant difference 


\section{DISCUSSION}

Cirrhosis represents a serious public health problem worldwide and they cause physical and psychological morbidity and mortality and also significant social costs [7].

The importance of patients' health related quality of life (HRQL) in medical practice is nowadays beyond dispute. The assessment of the physical, psychological and social functioning of the patient in terms of the impact of disease is an essential part of clinical diagnosis, a major determinant of therapeutic choices, a measure of their efficacy, and a guide in planning long-term care [8].

The study was conducted to assess the impact of cirrhosis on a weighted score of health-related quality of life in those patients. This study found that, there was high statistical significance between the cirrhotic patients and control groups as regard past history of hematemesis and jaundice $(\mathrm{P}<0.001)$. Past history of anti bilharzial treatment was statistically significantly present in the cirrhotic patients in comparison with control groups $(\mathrm{P}<0.05 \%)$.

There was a high statistically significant difference of the short form 36 (SF-36) questionnaires as regarding physical functioning, role of limitation due to physical functioning, bodily pain scale, general health scale of quality of life between group 1 (Child A), group 2 (Child B), group 3 (Child C) and in group 4 (Controls). This agreed with other study done by Gao et al. [9] who selected a total of 392 Chinese patients with CLD and 91 healthy controls and showed that mean \pm SD regarding physical functioning in controls, Child A,B,C was 91.7 $\pm 9.3,85.2 \pm 17.8$, $72.4 \pm 21.5,55.7 \pm 25.9$ respectively and regarding physical functioning limitation the mean $\pm \mathrm{SD}$ in controls, Child A ,B,C was $88.2 \pm 13.2,73.3 \pm$ $22.2,61.6 \pm 21.5,48.7 \pm 25.8$ respectively $(\mathrm{P}<0.001)$. In a study done by Marchesini et al. [10] on 544 patients with cirrhosis ; all domains of health-related quality of life, except pain, were altered in cirrhosis (by 9\%-42\%). The significance in our study in bodily pain scale may be explained to the occurrence of sever ascites and malnutrition and neuritis in group 3 Child $\mathrm{C}$ than the other groups.

There was no statistical significance between group 1 (child A) and group 4 (controls) in all scores of the short form 36 (SF-36) questionnaires (physical functioning, role of limitation due to physical functioning, bodily pain scale, general health scale, vitality scale, social functioning scale, mental health scale) of quality of life with high significance in emotional problems limitation scale. This may be due to that child A patients has better clinical and laboratory investigations than child B \& C.This agreed with other study done by Sobhonslidsuk et al. [11] on total of 200 subjects with 150 CLD and 50 normal subjects. The ratio of cirrhotic patients classified as Child A:B:C was 37(50\%): 26(35\%): 11(15\%). The highest scores of CLDQ domains were in the normal group, scores were lower in the compensated group and lowest in the decompensated group.

There was high statistically significant difference on the short form 36 (SF-36) questionnaires as regarding to vitality scale, social functioning scale, role of limitation due to emotional problems scale, mental health scale of quality of life between Child A, Child B, Child C and Controls with $P$ value $<0.001$. This agreed with other study done by Gao et al. [9] that selected a total of 392 Chinese patients with CLD and 91 healthy controls and showed that mean \pm SD regarding vitality scale in controls, Child A,B, C was $79.0 \pm 9.5, \quad 74.3 \pm 13.1, \quad 70.8 \pm 13.1, \quad 59.3 \pm 20.1$ respectively and as regard emotional problems was $92.4 \pm 9.8,86.2 \pm 15.8,84.6 \pm 17.9,74.2 \pm 26.8$ respectively with $\mathrm{P}<0.001$. Also this agreed with the study done by Younossi et al. [12] using social functioning scales and found that there was a gradient correlates between patients without cirrhosis, Child's A cirrhosis, and those with Child's $\mathrm{B}$ or $\mathrm{C}$ cirrhosis and CLDQ. Nguyen et al. [13] showed that Primary caregivers of patients with advanced liver disease have significantly lower SF-36 mental health scores compared with the general population.

There was statistically significant positive correlation between the education and the parameters of the SF-36 scores as regard to the vitality (energy/ fatigue) scale and physical functioning scale $(\mathrm{p}$ value $<0.05)$ as shown in table (3). Zandi and his colleagues [14] found that the educational and self care programs had positive effects on the quality of life of cirrhotic patients. Extensive educational and self-care programs along with long-term follow up such as the program conducted in their study are suggested. This significance may be explained by that low education cause ignorance of the nature of the chronic liver diseases and lack of follow up. 
There was statistical significant positive correlation between the occupation and the parameters of the SF-36 scores as regard to the vitality (energy/ fatigue) scale and physical functioning scale( $p$ value $<0.05$ ) as shown in table (4).This agreed with the reported results by Sobhonslidsuk [15], his study conducted on two-hundred and fifty patients with CLD and fifty normal subjects and the numbers of low educated, unemployed and poor health perception had deteriorated HRQL and increased significantly from chronic hepatitis to Child's Classes A, B and C.

\section{CONCLUSION}

Finally, Cirrhotic Patients had a poor baseline quality of life as indicated by the deterioration in SF-36 questionnaire which was related to increasing disease severity (Child scoring), educational level and occupation. So, we recommend that increasing the educational level and proper occupation could increase the vitality and physical functioning of quality of life of those patients.

Funding: None.

Conflicts of interest: The authors declare that there is no conflict of interest.

Ethical approval: Was granted by the Institutional Review Board and informed consent was obtained from each patient prior to inclusion in the study

\section{REFERENCES}

1- Van der Plas SM, Hansen BE, de Boer JB, ijnen T, Passchier J, de Man RA,Schalm SW. The Liver Disease Symptom Index 2.0; validation of a disease-specific questionnaire. Qual Life Res 2004; 13(8):1469-81.

2- Bergner M. Quality of life, health status, and clinical research. Med Care 1989; 27:S148.

3- Borgaonkar MR ,Irvine EJ. Quality of life measurement in gastrointestinal and liver disorders. Gut 2000; 47: 444-454.

4- Zautra A, Goodhart D. Quality of life indicators: a review of the literature. Commun Ment Health Rev 1979; 4(1): 3-10.

5- Younossi ZM, Boparai N, McCormick M, Price LL, Guyatt G. Assessment of utilities and healthrelated quality of life in patients with chronic liver disease. Am J Gastroenterol 2001; 96(2):579-83.
6- Ware J, Kosinski M, Keller S. SF-36 Physical and Mental Health Summary Scales. a User's Manual. Boston: The Health Institute, New England Medical Center 1994 : 21-35.

7- Roderick P, Parkes J , Rosenberg W: The epidemiology and health care burden of chronic liver diseases. Final report to British liver Trust and Foundation for liver Research 2004; 30:7075 .

8- Williams ME. Why Screen for Functional Disability in Elderly Persons?. Ann Intern Med 1990; 112(9):639-640.

9- Gao R, Gao F, Li G, Hao JY. Health-related quality of life in chinese patients with chronic liver disease.Gastroenterol Res Pract. 2012;2012:516140.

10-Marchesini G,Bianchi G, Amodio P. Factors associated with poor health-related quality of life of patients with cirrhosis. Annual Meeting of the Italian Association for the Study of the Liver 1999 ; 17-19, 170-178.

11-Sobhonslidsuk A, Silpakit C, Kongsakon R, Satitpornkul P, Sripetch C. Chronic liver disease questionnaire: translation and validation in Thais. World JGastroenterol. 2004 Jul 1;10(13):1954-7.

12- Younossi ZM, Guyatt G, Kiwi M, Boparai N, King D. Development of a diseasespecific questionnaire to measure health related quality of life in patients withchronic liver disease. Gut. 1999;45(2):295-300.

13- Nguyen DL, Chao D, Ma G, Morgan T. Quality of life and factors predictive of burden among primary care givers of chronic liver disease patients. Ann Gastroenterol. 2015 ;28(1):124129.

14-Zandi M, Adib-Hajbagheri M, Memarian R, Nejhad AK, Alavian SM. Effects of aself-care program on quality of life of cirrhotic patients referring to Tehran Hepatitis Center. Health Qual Life Outcomes. 2005 May 18;3:35.

15-Sobhonslidsuk A, Silpakit C, Kongsakon R, Satitpornkul P, Sripetch C,Khanthavit A. Factors influencing health-related quality of life in chronic liver disease. World J Gastroenterol. 2006 Dec 28;12(48):7786-91.

Peer reviewers: Hala I. M. Hussein ; Assistant Professor of Tropical Medicine, Faculty of Medicine, Zagazig University,

Egypt.Editor: Tarik Zaher; Professor of Tropical Medicine, Faculty of Medicine ,Zagazig University, Egypt. 